\title{
Mechanical Property of Plastic Lumber Produced from Recycled High Density Polyethylene (HDPE)
}

\author{
Birhanu Beshah*, Aychiluhim Mitiku, Michael Chernet, Mekdes Assefa, Mezekeir Addisu
}

School of Mechanical and Industrial Engineeirng, Addis Ababa Institute of Technology, Addis Ababa University, P.O.Box:7754, Addis Ababa Ethiopia

\section{Abstract}

Recycling is a strategy to combat environmental pollution due to plastic wastes. Of the many plastic wastes, researchers confirmed the possibility to produce plastic lumber from used HDPE plastics. The aim of this study is to experimentally determine the mechanical property of the plastic lumber produced from pure HDPE and its composite with wood to proof usability and applicability for different purpose. The experiment considered different conditions. Pure plastic lumber and wood plastic composite lumber is initially produced and examined under room temperature and below room temperature. Under each condition, bending, tensile and impact strength were examined. For each test eight specimens were prepared based on international standards and the experiments were conducted using standard testing machines. The result shows that pure plastic lumber has demonstrated superior load carrying capability, tensile load resistance capability and impact load resistance at room temperature. Moreover, the pure plastic lumber has an elastic nature and the wood composite has a brittle nature. In both cases the mechanical property of the plastic lumber permits to use for different applications. This has been also tested and resulted in similar phenomena at $2^{0} \mathrm{C}$ below room temperature.
\end{abstract}

Copyright@2014 STAR Journal. All Rights Reserved.

\section{Article Information}

\section{Article History:}

Received : 12-02-2014

Revised : 20-03-2014

Accepted : 25-03-2014

Keywords:

Plastic Lumber

HDPE

Wood Plastic Composite

*Corresponding Author:

Birhanu Beshah

E-mail:

birhanu.beshah@aait.edu.et

\section{INTRODUCTION}

Plastic waste management has become a major strategic issue for the polymer industry; it accounts for approximately $7 \%$ of the weight of all discarded products. Their impact on the environment is considerable, due to the low density, hollow shape one-way packaging, and the volume which is much greater than other waste products of similar weight. Approximately, $65 \%$ of all urban plastic waste consists of High Density Polyethylene (HDPE), Low Density Polyethylene (LDPE) and Polypropylene (PP). These plastic residues have also influences on economic and political aspects. Recycling of plastic wastes into a useable product of any sort will contribute in mitigating those challenges. With the growth of plastics usage in daily life, plastic recycling appear to be the most promising method to either meet the future demands for polymeric products or to reduce environmental pollution (Ehrig, 1992).

Comparatively, HDPE has high density relative to other polymers, with a specific gravity of 0.95 . HDPE is relatively hard and resistant to impact and can be subjected to temperatures of up to $120^{\circ} \mathrm{C}$ without being affected. HDPE is not auto cleavable, unlike Polypropylene (PP). Autoclaving conditions are used to sterilize equipment and supplies by subjecting them to high pressure saturated steam at $121^{\circ} \mathrm{C}$ for around 1520 minutes depending on the size of the load and the contents (http://plastics.ides.com/). These durable properties make it preferable for heavy duty containers.
Primarily, HDPE is used for milk containers, as well as Tupperware, shampoo bottles, bleach bottles, motor oil bottles, etc. Since HDPE does not also absorb liquid readily, it is good barrier material for liquid containers. Almost a third (about eight million tons) of HDPE produced worldwide is used for these types of containers. Due to these advantageous properties of HDPE, the focus of this study is on recycling HDPE plastic wastes.

Plastics can be recycled for different applications. One of these products is plastic lumber; a wood like product made from recovered plastic or recovered plastic mixed with other materials, which can be used as a substitute for concrete, wood, and metals. Post-consumer recycled plastic, from products such as bottles, milk jugs, pails, etc. is melted at about $200^{\circ} \mathrm{C}$, and then extruded through a mold to form dimensional lumber. $80 \%$ of this recycled plastic is HDPE (Robbins E. Alan, 1998; Shigley, 2009).

The new products produced by recycling the different plastics types hold different characteristics depending on the type of the plastic used and the process followed. The physical nature as well as its chemical composition will be carefully studied to develop the material character. This study aim at studying mechanical property of a plastic lumber produced from recycled HDPE. The most critical mechanical property tests are bending, tensile and shire strength. Therefore, the strength of the plastic lumber is determined by conducting bending, tensile and impact 
Birhanu et alo,

strength test with standard machines. The outcome will be helpful to determine use and application of recycled plastic lumber for different purpose and case.

\section{MATERIALS AND METHODS}

In order to achieve the objective of this study, a stepby-step standard procedure has been adopted. Primarily, used plastics were collected and HDPE plastics were sorted by physical observation and chemical test where there is no printed information explaining the property of the waste. Second, cleaning, drying and shredding. Third, using $66 \%$ less energy than is used in virgin plastic production, the shredded plastics were recycled and extruded to produce the plastic lumber. Finally, specimens to test bending, tensile and impact strength were prepared and the tests were carried out using standard machines.

Specimens were prepared from plastic lumber produced from pure HDPE and 30\% wood and $70 \%$ HDPE composites (wood plastic composite). Bending, tensile and impact strength of these two types of lumber were tested under room temperature $\left(14^{\circ} \mathrm{C}\right)$ and below room temperature $\left(2^{0} \mathrm{C}\right)$. To control variation due to different factors two specimens were prepared for each case. The total specimens prepared were $24-12$ for pure HDPE and 12 for wood and HDPE composite. These means eight tests were carried out to examine bending,
Sci. Technol. Arts Res. J., Jan-March 2014, 3(1): 141-144

tensile and impact strength of the plastic lumber produced from recycled plastics. Normally, one specimen is sufficient to carry out the test, but to make it sure; this research used two specimens for each test.

Specimens were prepared based on international standards - for bending test, ASTM D790-10; for tensile test, ASTM D638; and for impact test, ASTM D256 were used (ASTM, )

\section{RESULTS}

The results from the bending, tensile and impact tests are presented in the following sections.

\section{Bending Test}

Three points testing was used to determine the load carrying capacity of specimen being suspended at two points and the load exerted to it at the middle. As stated in the methodology section, this test was done on lumber produced from pure HDPE and $30 \%$ wood HDPE composite specimens both at room temperature and below room temperature. From the experiment, important observations have been made. The loading capacity, young's modules (E) and deflections $(Y)$ are extracted from the universal testing machine and summarized in Table 1.

Table 1: Result of the bending experiment.

\begin{tabular}{ccccc}
\hline & \multicolumn{4}{c}{$\mathrm{T}_{1=}$ Room Temperature } \\
\cline { 2 - 5 } & \multicolumn{3}{c}{ Pure HDPE } & \multicolumn{2}{c}{ 30\% WPC } \\
\cline { 2 - 5 } & Specimen 1 & Specimen 2 & Specimen 3 & Specimen 4 \\
\hline Load[KN] & 7.1 & 6.85 & 4.2 & 3.8 \\
Young's modulus[E][Gpa] & 0.0616 & 0.064 & 0.04 & 0.05 \\
Deflection $(\mathrm{y})\left(10^{-4}\right)$ & 6.341 & 6.12 & 3.75 & 3.39 \\
\hline
\end{tabular}

From the bending test result, the behavior of HDPE plastic lumber during loading resulted in $14.61 \mathrm{~N} / \mathrm{mm}^{2}$ and $14.7 \mathrm{~N} / \mathrm{mm}^{2}$ specimen 1 and 2 respectively. From this result it is concluded that as the temperature decreases the specimen losses its ductility nature and observes brittleness. The result obtained for WPC Lumber at both temperature ranges and specimens are $12.5 \mathrm{~N} / \mathrm{mm}^{2}$ and $12 \mathrm{~N} / \mathrm{mm}^{2}$. Similarly, as the temperature drops the molecules of the specimen becomes more compact making it to be more brittle. The brittleness is due to the fact that the WPC lumber approaches the glass transition temperature of HDPE.

A lumber produced from pure HDPE has a certain amount of elastic behavior where as lumbers produced from composite are stiffer and lacks elastic behavior. In both the cases, at room temperature the elasticity decreases. But in general the pure HDPE plastic is more capable of handling a bending load rather than the wood composite lumber. Moreover, the strain is found to be directly proportional to the stress applied which depicts linear relationship.

\section{Tensile Test}

On tensile test, hanging load carrying capacity of the specimens was determined to understand the elastic behavior. A total sum of 8 specimens is considered for a tensile test of product consisting pure HDPE and its wood composites. Load, UTS, and Young's modulus are extracted from the test machine and summarized in Table 2.

Similar to the bending test, the wood composite has very little capability to resist the tensile load. The plot is the combination of all the tensile strength tests (Figure 1). The first curve designates the pure HDPE lumber value at room temperature of about $42 \mathrm{~N} / \mathrm{mm}^{2}$. The last and the sharp edge curve is $30 \%$ WPC with a result of $14 \mathrm{~N} / \mathrm{mm}^{2}$.

There is a significant reduction in mechanical property especially at higher strain values with a percentage increment of wood. This might be attributed to the presence of impurities which impart local dislocations or might be due to manufacturing limitations such as insufficient mixing which in turn leads to insufficient dispersion of wood particles into the HDPE matrix.

Table 2: Result on the tensile test.

\begin{tabular}{ccccc}
\hline & \multicolumn{3}{c}{ T $_{\mathbf{1}}$ Room Temperature } \\
\cline { 2 - 5 } & \multicolumn{2}{c}{ Pure HDPE } & \multicolumn{2}{c}{ 30\% WPC } \\
\cline { 2 - 5 } & Specimen 1 & Specimen 2 & Specimen 3 & Specimen 4 \\
\hline Load $[\mathrm{KN}]$ & 2.393 & 2.477 & 1.42 & 1.96 \\
UTS [ $\sigma_{\max }[\mathrm{Kpa}]$ & 0.0308 & 0.032 & 0.02 & 0.025 \\
Young's modulus[E][Mpa] & 0.0616 & 0.064 & 0.04 & 0.05 \\
\hline
\end{tabular}




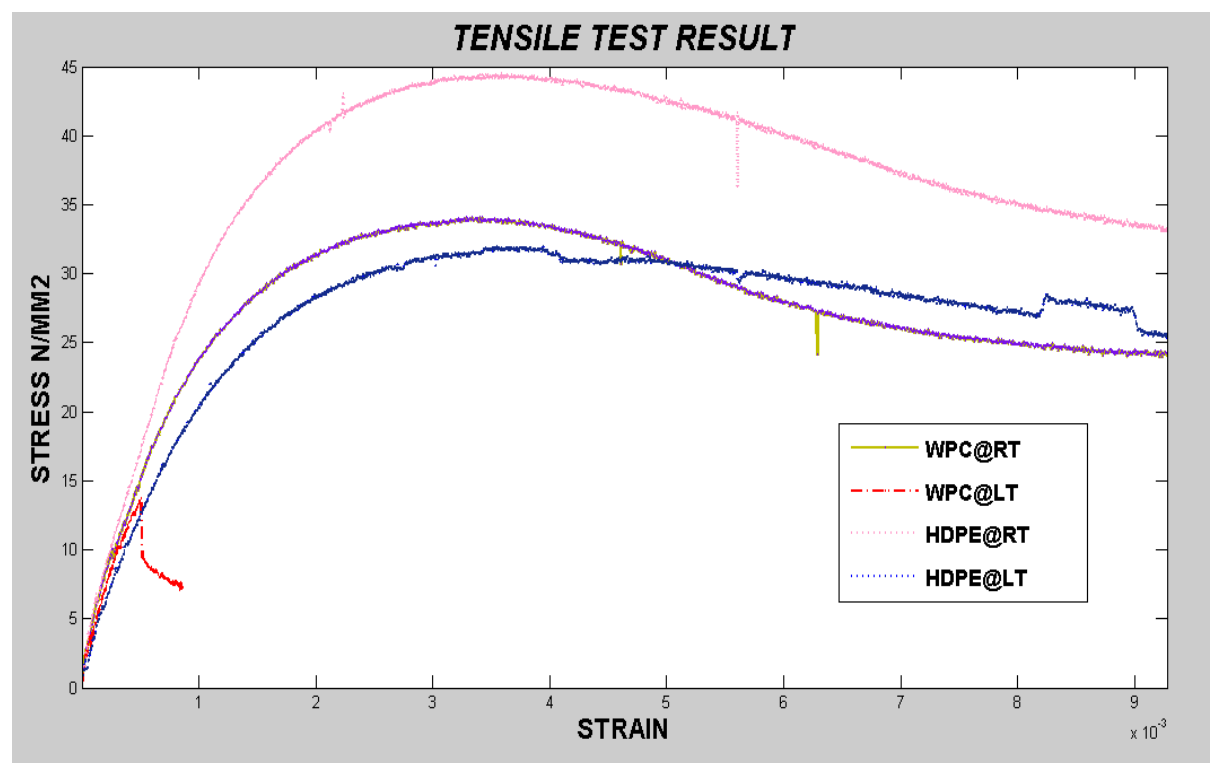

Figure 1: Stress Strain relationship for the entire tensile test.

\section{Impact test}

As we have mentioned earlier, impact load testes were done on both types of specimens (i.e. lumber produced from pure HDPE and wood composite) at two specified temperatures. The results are summarized on Table 3 below. In this test the pure HDPE withstands certain amount of force while the wood composite lumber has almost zero resistance over the impact load.

At room temperature with no pressure being mounted, it has a value of resistance. This value might be good but it has to be enhanced by decreasing the plastic lumbers characteristics of rigidity. Below room temperature with no pressure being mounted the value of the lower resistance is well below from the result of the room temperature data. This is because the material by itself has the characteristics of high brittleness when the temperature drops to $-2^{\circ} \mathrm{C}$; it has added certain brittleness after being recycled. This brittleness has made the HDPE lumber to be easily broken when it is exposed to bending. Energy absorbing capacity of the pure HDPE is also very high as compared to the wood composite.

Table 3: Results from the impact test.

\begin{tabular}{ccccc}
\hline & \multicolumn{3}{c}{ T $_{\mathbf{1}}$ Room Temperature } \\
\cline { 2 - 5 } & \multicolumn{2}{c}{ Pure HDPE } & \multicolumn{2}{c}{ 30\% WPC } \\
\cline { 2 - 5 } & Specimen 1 & Specimen 2 & Specimen 3 & Specimen 4 \\
\hline Load exerted(Kg/m) & 2.5 & 2.67 & 0.5 & 0.5 \\
\hline Young's modulus[E][Gpa] & 0.0616 & 0.064 & 0.04 & 0.05 \\
\hline Energy absorbed(J) & 24.5 & 26.166 & 4.9 & 4.9 \\
\hline
\end{tabular}

\section{DISCUSSION}

Three of the selected experiment types were performed at two temperature levels. The two temperature situations will have a vital role in understanding the performance and endurance of the lumber at different temperature ranges. The test performed at room temperature helps us to understand and analyze the lumbers physical ability of its due time in every day performance. While the temperature below the room temperature helps us to understand and analyze the characteristics of the lumber when it is functioning at lower climatic condition. From the experiment generally, mechanical properties of the recycled plastic at room temperature are found to be better than that of its properties at below room temperature.

Moreover, the mechanical property of the recycled material was below the expected range. One possible reason for this is the process of recycling the plastic. Practically, there was no pressure exertion on the plastic material before it cools. In the absence of pressure as a direct negative impact on the material, it has created loose of integration in the product. Thus there was a presence of porosity caused by puffing of the plastic with air bubbles. This problem makes the product to have less resistivity towards any load types.

Although WPC has demonstrated week mechanical property, they have good machining condition and can be shaped using conventional woodworking tools. WPCs are often considered a sustainable material because they can be made using recycled plastics and the waste products of the wood industry. They can however be recycled easily in a new wood-plastic composite, much like concrete. One advantage over wood is the ability of the material to be molded to meet almost any desired shape. A WPC member can be bent and fixed to form strong arching curves. The mechanical behavior of WPCs is most similar to neat polymers. This means that they have a lower strength and stiffness than wood.

\section{CONCLUSION}

In conclusion, plastic recycling has become a new focus throughout the globe because of the need to recover plastic and reuse them. In this study attempt has been made to produce plastic lumber from recycled HDPE plastic. The lumber may be used for furniture making and similar application. In order for lumber to be used and 
Birhanu et alo,

sustain certain load, the mechanical properties of the lumber (pure HDPE lumber and WPC lumber) have to be examined through experimental procedures. The experiments that are carried out to evaluate mechanical property were, bending, tensile, and impact test.

From the bending test result, the pure HDPE lumber has more elastic nature making it to be ductile and not to be broken easily during bending loading. The WPC is more brittle and is easily broken when it's exposed to bending load.

The tensile test demonstrated the elastic behavior and tensile load carrying capacity of the two lumber types. The temperature factor has very little effect on the result of WPC lumber. From this we can conclude that when the two type of lumber are subjected to some tensile loading condition the pure HDPE lumber shows a significant value difference from the WPC lumber and has proven itself to have a better tensile load resistance capability.

Impact test of specimens for pure HDPE lumber are $2.5 \mathrm{Kg} / \mathrm{m}$ and $2.67 \mathrm{Kg} / \mathrm{m}$ at room. For the WPC lumber $0.5 \mathrm{Kg} / \mathrm{m}$ and $0.5 \mathrm{Kg} / \mathrm{m}$. But the proportion factors have shown a significant difference between the two types of lumbers. The HDPE lumber has more energy absorbing capacity when compared to the WPC lumber.

The HDPE plastic lumber can be used as a structural purpose beside furniture products just by enhancing its strength capability. This strength capability of the plastic may be done through many ways starting from, manufacturing processes, selection of matrix pattern,
Sci. Technol. Arts Res. J., Jan-March 2014, 3(1): 141-144

composite material selection, wood plastic composition percentage selection, etc. avoiding moisture content from the plastic. In addition to this, since production process of wood plastic composite uses simple technology and both the plastic and wood are wastes plastic lumber is feasible both economically and technically.

\section{REFERENCES}

ASTM D256. Standard Test Methods for Flexural Properties of Unreinforced and Reinforced Plastics and Electrical Insulating Materials. American Standards for Testing Material International, West Conshohocken, PA, USA.

ASTM D638. Standard Test Methods for Flexural Properties of Unreinforced and Reinforced Plastics and Electrical Insulating Materials. American Standards for Testing Material International, West Conshohocken, PA, USA.

ASTM D790. Standard Test Methods for Flexural Properties of Unreinforced and Reinforced Plastics and Electrical Insulating Materials. American Standards for Testing Material International, West Conshohocken, PA, USA.

Ehrig, R.J. (1992). Plastics recycling - Products and processes, $1^{\text {st }}$ ed., Hanser Publications. New York.

Robbins E. Alan (1998). State of the Recycled Plastic Lumber Industry, Annual Meeting of the Plastic Lumber Trade Association.

Shigley, J. E. (2009), Mechanical design of machinery, 7th edition, published by McGraw-Hill.

Typical Properties of Polyethylene. http://plastics.ides.com/ generics/27/c/t/polyethylene-pe-properties-processing/ $\mathrm{sp} / 12$ retrieved on 23-12-2013. 